\title{
Determination of Soil Texture by Laser Diffraction Method
}

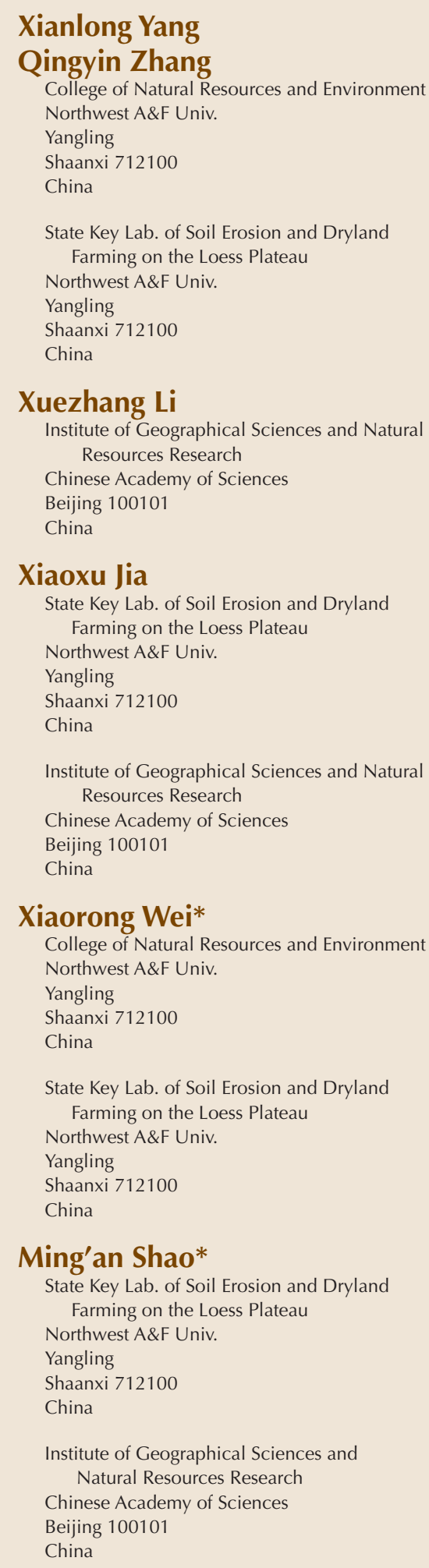

\section{Xiaorong Wei*}

College of Natural Resources and Environment Northwest A\&F Univ.

Yangling

Shaanxi 712100

China

State Key Lab. of Soil Erosion and Dryland Farming on the Loess Plateau

Northwest A\&F Univ.

Yangling

Shaanxi 712100

China

The laser-diffraction method (LDM) can rapidly determine soil particlesize distributions (PSDs), but LDM-derived PSDs cannot be directly used to classify soil textures by referring to the standards of the classical sievepipette method (SPM). Our objectives were to explore calibration models for converting PSD data from LDM (volume, \%) to SPM (mass, \%), and to evaluate the precision of textural classification by using LDM data. We determined the PSDs using both methods for 235 soil samples of various textures collected from three typical land uses, on the Loess Plateau of China. The LDM generally underestimated clay fractions by an average of $45.1 \%$, and overestimated silt fractions by an average of $18.3 \%$ compared with SPM. Differences in PSD data between the two methods, indicated by coefficient Cs, increased with increasing clay contents for the 235 samples $(P<0.05)$. Three calibration models could, however, convert the clay, silt, and sand contents from the volume percentage (LDM) to the mass percentage (SPM). After the conversion, the mean coefficient $C$ between the two methods decreased from 7.9 to $4.1 \%$ for the validation samples $(n$ $=78$ ). The distributions of soil textures within the USDA textural triangle agreed well in $\mathbf{7 1}$ of the $\mathbf{7 8}$ samples, for measured and converted PSD data. The three types of land use did not affect the differences between measured and converted PSD data $(P>0.05)$. Soil textures can thus be rapidly determined by converting PSD data from the faster volume-based LDM to data equivalent to the mass-based SPM, independent of land-use type.

Abbreviations: $\mathrm{D}_{\mathrm{B}}$, bulk density; LDM, laser-diffraction method; $\mathrm{PSD}$, particle-size distribution; $\mathrm{RI}$, refractive index; SAI, soil absorption index; SOC, soil organic carbon; SPM, sieve-pipette method; SRI, soil particle refractive index.

$\mathrm{P}$ article-size distribution is a fundamental physical property of soil and strongly affects the classification of soil texture, pore distribution, hydraulic conductivity, stocks of soil organic carbon (SOC), and thermal and sorptive properties (Arya and Paris, 1981; Eshel et al., 2004; Hajnos et al., 2006; Ryżak and Bieganowski, 2011; Wang et al., 2013a, 2013b; Wei et al., 2013a, 2014). The sieve method combined with the classical sedimentationbased pipette method (SPM) has been adopted for the last several decades as the international standard for determining soil PSDs (Cooper et al., 1984; Wen et al., 2002). The sieve method defines particle diameter as the length of the side of the smallest square hole through which a particle can pass (Eshel et al., 2004). This method is commonly used to separate the sand fractions from the clay and silt fractions by drying and weighing the material remaining on the sieve (Gee and Bauder, 1986). The pipette method defines the diameter of a soil particle as the size of a sphere that settles in a liquid at the same rate as the particle, the socalled Stokes diameter (Muggler et al., 1997). This method is commonly used to determine clay and silt fractions (Eshel et al., 2004).

The classical sedimentation-based SPM for determining PSDs, however, has many practical shortcomings. 1. It is time consuming, especially for fractions $<2 \mu \mathrm{m}$, and results become unreliable for particles $<1 \mu \mathrm{m}$ due to the

Soil Sci. Soc. Am. J. 79:1556-1566

doi:10.2136/sssaj2015.04.0164

Received 29 Apr. 2015.

Accepted 3 Aug. 2015.

*Corresponding author (xrwei78@126.com; shaoma@igsnrr.ac.cn).

(c) Soil Science Society of America, 5585 Guilford Rd., Madison WI 53711 USA. All Rights reserved. 
influence of Brownian motion on the rate of sedimentation (Allen, 1981; Di Stefano et al., 2010). 2. Large soil samples $(10-20 \mathrm{~g})$ are required to obtain reliable results (Eshel et al., 2004). 3. The densities of particles of different sizes are commonly assumed to be a constant $\left(2.65 \mathrm{Mg} \mathrm{m}^{-3}\right)$, which is not true for soil and which has been reported to vary from 1.66 to $2.99 \mathrm{Mg} \mathrm{m}^{-3}$ (Vdović et al., 2010; Miller and Schaetzl, 2012; Wang et al., 2013a). 4. Results can vary with laboratory technique, equipment, or operator (Wen et al., 2002). These inherent disadvantages consequently render SPM incapable of analyzing a large number of samples rapidly.

Over the last few decades, new techniques have been developed for determining soil PSDs: the LDM, electrical sensing, X-ray sedimentation, and image analysis (Singer et al., 1988; Vitton and Sadler, 1997). Of these, LDM is the most popular and widely used because of its superior qualities compared with the classical SPM, such as rapid analysis, small size $(<1 \mathrm{~g})$ of samples, high repeatability, and a wide particlesize range (Özer et al., 2010). More importantly, LDM provides a continuous PSD curve rather than an arbitrary division of particle sizes, as in the traditional SPM. This advantage alone is valuable for more detailed data analyses and transformations among the various classification systems (Wang et al., 2013a). However, the notable limitation of the LDM measurement is the under-reporting of clay content and the dependence on well-described optical properties of refractive index and absorption, and also the high instrument's cost and lack of standard operation in soil analysis (Campbell, 2003; Makó et al., 2014). The LDM measures the volume percentage of a size fraction and two optical models (Fraunhofer and Mie) are commonly used to calculate PSDs (Eshel et al., 2004; Özer et al., 2010). Both theories assume spherical shape of particles. The Fraunhofer theory starts from the principle that there is only diffraction and no refraction and thus is inapplicable when particle diameter is close to the wavelength of light as the refraction of particles in this size range become considerable (Wen et al., 2002). The Mie theory is a solution of the Maxwell equations describing propagation of the electromagnetic wave of light in space. This theory provides a solution for the case of plane wave on a homogeneous sphere of any size (Eshel et al., 2004; Di Stefano et al., 2010). The principle of LDM is that soil particles diffract the beam of monochromatic light that passes through the soil suspension placed in a sample cell (Makó et al., 2014). The angle of diffraction is inversely proportional to particle size, and the intensity of the diffracted beam at any angle is a measure of the number of particles with a specific cross-sectional area in the beam's path (Konert and Vandenberghe, 1997; Eshel et al., 2004; Di Stefano et al., 2010).

The advantages of LDM over the traditional sedimentation-based SPM for determining soil PSDs have thus attracted the interest of soil scientists. The PSDs obtained by LDM, however, have been widely reported to differ from those obtained by SPM (Eshel et al., 2004; Yang et al., 2009; Kowalenko and Babuin, 2013). For example, LDM underestimated clay fractions and overestimated silt fractions compared with SPM (Konert and Vandenberghe, 1997; Beuselinck et al., 1998; Eshel et al., 2004; Yang et al., 2009). A few study, however, reported good agreement between the two methods (Wu et al., 1993; Muggler et al., 1997; Cheetham et al., 2008). These differences in PSDs between the two methods were due to differences in methodology, mineralogy, refraction index values of the samples, and particle morphology (Zobeck, 2004).

Soil PSD data in most databases are derived by SPM which are based on Stokes' Law (Gee and Or, 2002; Bah et al., 2009). Decades of use have identified relationships between SPM PSD data and soil properties, but little for LDM data. We thus cannot directly determine the texture of a soil by using PSD data derived by LDM (volume, \%), because the current classification systems of soil texture (e.g., USDA) are typically based on PSD data derived by SPM (mass, \%). Various studies have thus compared PSDs between the two techniques and have attempted to produce models for converting LDM PSD data to SPM data (Konert and Vandenberghe, 1997; Eshel et al., 2004; Wang et al., 2013a). These calibration relationships enable researchers to compare laser data with the large amount of literature available on sediment texture based on settling technique (Ramaswamy and Rao, 2006). Most of these comparisons and models, however, were based on small soil samples from a single type of land use and therefore had limited applicability for conversion to larger-scale PSDs. Moreover, the feasibility and precision of soil texture determination by using LDM converted PSD data has less been evaluated.

Therefore, we collected a total of 235 soil samples from three typical types of land use (grassland, cropland, and forest) at six sites on the Loess Plateau of China. Our specific objectives were: (i) to understand how and to what extent the PSD data differed between LDM and SPM, (ii) to identify whether there exist significant functional relationships for PSDs derived by LDM and SPM, and (iii) to evaluate the feasibility of rapidly determining soil texture by converting LDM PSD data (volume, \%) to SPM data (mass, \%) based on the previously established relationship models.

\section{MATERIALS AND METHODS Sample Collection and Preparation}

A total of 235 soil samples from three typical land uses and different types of soil texture were collected from Fufeng County $(n=26)$, Yongshou County $(n=29)$, Bin County $(n$ $=47)$, Fu County $(n=28)$, Yan'an City $(n=21)$, and Shenmu County $(n=84)$ on the Loess Plateau of China (Fig. 1). Fiftynine samples were collected from grasslands (e.g., Medicago sativa and Stipa capillata), 67 from croplands (e.g., Zea mays and Setaria italica), and 109 from forests (e.g., Caragana korshinskii and Robinia pseudoacacia; Table 1). The samples were collected from a depth of 0 to $20 \mathrm{~cm}$ with a tube auger $5.0 \mathrm{~cm}$ in diameter. All samples were air-dried, gently crushed, 


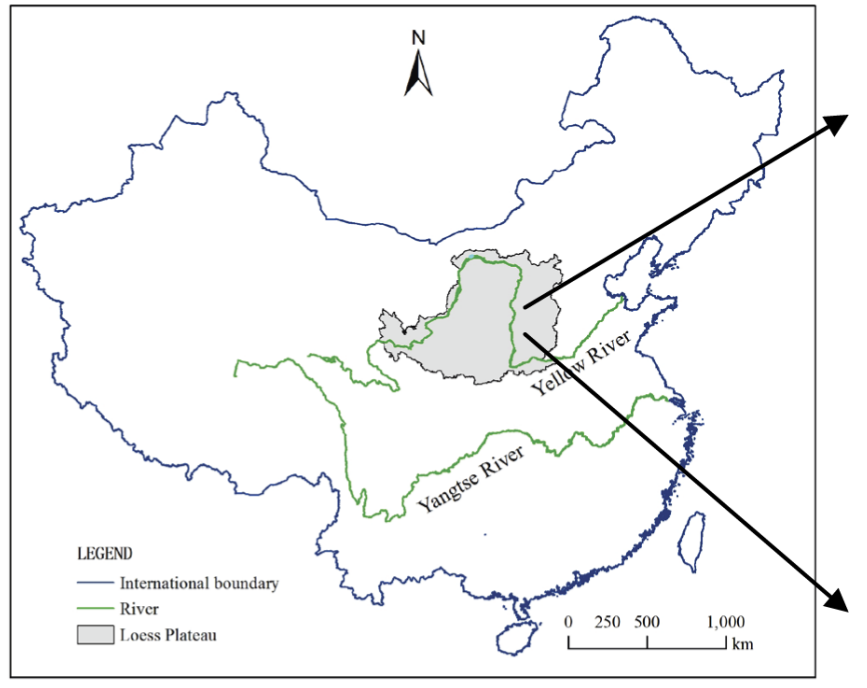

Fig. 1. Map of the study area and sampling sites of the 235 soil samples.

and then dry-sieved using a 2-mm mesh sieve to remove the coarse fragments. The SOC content was determined using the Walkley-Black method (Nelson and Sommers, 1982). Soil bulk density $\left(D_{B}\right)$ was measured at the same depths using a stainless-steel cutting ring $5.0 \mathrm{~cm}$ high by $5.0 \mathrm{~cm}$ in diameter (Wei et al., 2013a, 2013b). The cores were weighed after drying at $105^{\circ} \mathrm{C}$ for $24 \mathrm{~h}$.

\section{Laboratory Particle-Size Distribution Determination}

Soil PSDs were determined for the 235 soil samples by both LDM and SPM. Each soil sample was properly subdivided into two subsamples: one for LDM and the other for SPM measurement. Sample quartering was used to perform the subdivision to obtain a good representative. The samples prepared for SPM measurement were incubated in 10\% (vol.) hydrogen peroxide for $48 \mathrm{~h}$, with occasional stirring (three to five times) to remove the organic material. Carbonates were then removed using $0.2 \%$ (vol) hydrochloric acid, and soil aggregates were dispersed using $0.5 \mathrm{~mol} \mathrm{~L}^{-1}$ sodium hexametaphosphate. Organic matter $(\mathrm{OM})$ and carbonates were not removed and sodium hexametaphosphate was not used to disperse the samples for LDM analysis.

For SPM, the pretreated samples ( $10 \mathrm{~g}$ per sample) were wet sieved through a $0.25-\mathrm{mm}$ sieve to obtain the coarser fractions $(2-0.25 \mathrm{~mm})$, by drying and weighing the material remaining on the sieve. The finer fractions $(<0.25 \mathrm{~mm})$ were then transferred to $1000-\mathrm{mL}$ graduated cylinders for pipette analysis. The cylinders were stored overnight in a small closed

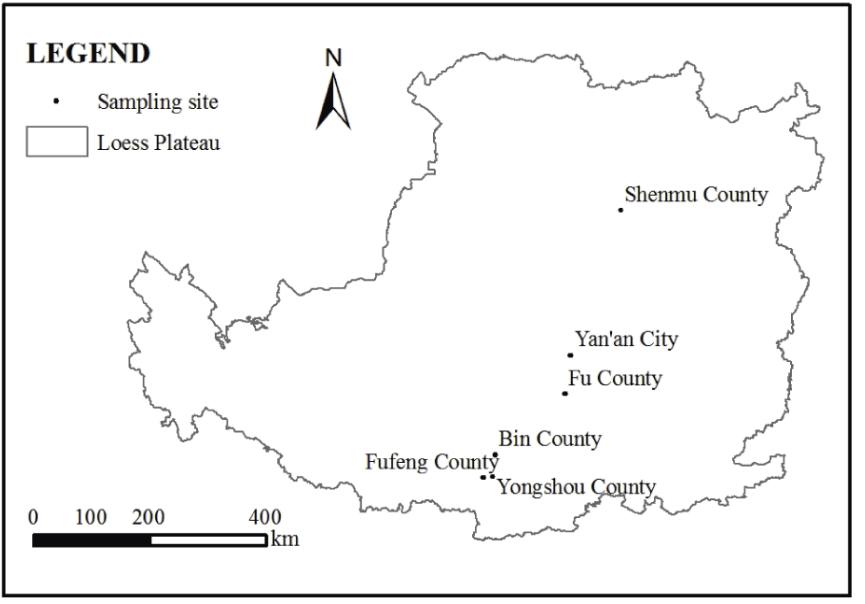

laboratory at a strictly controlled air temperature of $20^{\circ} \mathrm{C}$. The amount of labor and time required for this method limited our analysis to five categories of particle sizes (2$0.25,0.25-0.05,0.05-0.02,0.02-0.002$, and $<0.002 \mathrm{~mm}$ ). Of these, the proportion of 0.25 - to $0.05-\mathrm{mm}$ size fraction was indirectly calculated by subtracting the proportions of the remaining four sizes $(2-0.25,0.05-0.02,0.02-0.002$, and $<0.002 \mathrm{~mm}$ ) from $100 \%$.

For LDM, the PSD was analyzed with a Mastersizer 2000 particle-size analyzer (Malvern Instruments, Worcestershire, UK). Two wavelengths of light were used in the Mastersizer: red $(633 \mathrm{~nm})$ and blue $(466 \mathrm{~nm})$. A single measurement lasted $30 \mathrm{~s}$ for the red and $30 \mathrm{~s}$ for the blue light. The instrument is equipped with a stirrer and an ultrasonic probe. The stirrer has a speed of $1500 \mathrm{rpm}$ and can prevent sedimentation of particles in the beaker, by circulating the sample in the measuring system and facilitating flow through the measuring cell. The ultrasonic probe with a maximum power of $35 \mathrm{~W}$ and a frequency of 40 $\mathrm{kHz}$ was used to disperse the samples (Ryżak and Bieganowski, 2011). This instrument provides continuous PSD curves with a resolution of particle size within the range 0.02 to $2000 \mu \mathrm{m}$ (Sochan et al., 2014). The PSDs were calculated using Mie theory due to the unsatisfactory determination of the clay fraction using the Fraunhofer model (De Boer et al., 1987; Loizeau et al., 1994). The Mie model takes into account phenomena of transmission through the particle and therefore requires three indices for a measurement. The refractive

Table 1. Physical and chemical properties of the 235 soil samples collected for the three land uses. +

\begin{tabular}{|c|c|c|c|c|c|c|c|c|c|}
\hline \multirow[b]{2}{*}{ Land use } & \multirow[b]{2}{*}{ Number of samples } & \multirow[b]{2}{*}{$\mathrm{D}_{\mathrm{B}}$} & \multirow[b]{2}{*}{ SOC } & \multicolumn{3}{|c|}{ SPM (mass) } & \multicolumn{3}{|c|}{ LDM (volume) } \\
\hline & & & & Clay & Silt & Sand & Clay & Silt & Sand \\
\hline & & $\mathrm{g} \mathrm{cm}^{-3}$ & $\mathrm{~g} \mathrm{~kg}^{-1}$ & & $-\%$ & - & & $\%$ & - \\
\hline Grassland & 59 & $1.41 \mathrm{a}$ & $5.6 \mathrm{~b}$ & $14.9 \mathrm{~b}$ & $19.5 \mathrm{~b}$ & $65.6 \mathrm{a}$ & $7.9 \mathrm{~b}$ & $24.1 \mathrm{~b}$ & $67.9 \mathrm{a}$ \\
\hline Cropland & 67 & $1.35 \mathrm{~b}$ & $6.4 \mathrm{~b}$ & $18.1 \mathrm{a}$ & $27.8 \mathrm{a}$ & $54.1 \mathrm{~b}$ & $10.2 \mathrm{a}$ & $32.2 \mathrm{a}$ & $57.6 \mathrm{~b}$ \\
\hline Forest & 109 & $1.24 \mathrm{C}$ & $12.2 \mathrm{a}$ & $19.4 \mathrm{a}$ & $30.4 \mathrm{a}$ & $50.2 \mathrm{~b}$ & $10.6 \mathrm{a}$ & $34.5 \mathrm{a}$ & $54.9 \mathrm{~b}$ \\
\hline
\end{tabular}

† Different letters within the same column indicate significant differences at $P<0.05$. $\mathrm{D}_{\mathrm{B}^{\prime}}$ bulk density; SOC, soil organic carbon; SPM, sievepipette method; LDM, laser-diffraction method. 
index (RI) of the suspending medium (water) had an RI of 1.33. The other two indices were soil-particle RI (SRI) and absorption index (SAI). The SRI represents the difference in the velocity of light through a tested material relative to the velocity in a vacuum, and the SAI represents the transparency and absorptivity of the tested materials. An SRI and SAI of 1.55 and 0.1 , respectively, are considered suitable for the laser-diffraction analysis of samples of naturally occurring sedimentary soil (Özer et al., 2010).

\section{Data Analysis}

The coefficient C, described by Goossens (2008), was used to synthetically evaluate the differences of the proportions of the five size fractions between LDM and SPM. The expression is as follows:

$$
C=\frac{1}{n} \sum_{i=1}^{n} \sqrt{\left(\mathrm{LDM}_{i}-\mathrm{SPM}_{i}\right)^{2}}
$$

where $n$ is the number of grain-size class; $\mathrm{LDM}_{i}$ is the percentage proportion of the $i$ th grain-size class, measured by LDM; $\mathrm{SPM}_{i}$ is the percentage proportion of the $i$ th grain-size class, measured by SPM.

The PSD data obtained by LDM and SPM were assigned to the size categories of the USDA textural classification system for clay, silt, and sand of $<0.002,0.05$ to 0.002 , and 2 to 0.05 $\mathrm{mm}$, respectively. The whole 235 paired PSD data, obtained by LDM and SPM, were then subdivided into two parts. Two thirds of the data $(n=157)$ were used to build up relationship models for converting PSD data from LDM (volume, \%) to SPM (mass, \%). The remaining one third of the data $(n=78)$ were used to validate the conversion models. The subdivision of the whole data sets was performed properly to assure that the samples in each subgroup, used for calibration and validation, were good representatives of the peculiarities of the whole data set. Relative mean squared error (RMSE) was calculated to evaluate the precision of these models. The 78 validation samples were then classified to textural types by reference to the soil-texture triangle based on the USDA classification system. Confusion matrix was used to illustrate the accuracy in correctly assigning the textural class starting from either LDM converted data or those provided by pipette method. Meanwhile, the kappa coefficient (Bishop et al., 1975) was calculated to evaluate the precision of the assignment.

A two-tailed Pearson correlation analysis determined the effect of the physical and chemical properties $\left(D_{B}\right.$ and clay, silt, sand, and SOC contents) on the difference in PSDs obtained by LDM and SPM. A one-way analysis of variance (ANOVA) followed by a least significant difference test $(P<0.05)$ examined the effect of land use on the difference in PSDs obtained by LDM and SPM. Paired-samples $t$ test (two-tails) was used to explore whether significant difference existed in PSDs between the two methods. A concatenate-fit model of multi-data across the three land uses was used to correlate the clay, silt, and sand contents obtained by the two methods using Origin 9.1 Pro (Origin Lab,Northhampton, ME). All statistical analyses were performed with SPSS 16.0 (IBM Corp., Armonk, NY).

\section{RESULTS AND DISCUSSION Comparison of Particle-Size Distributions between Laser-Diffraction Method and Sieve- Pipette Method}

The mean contents of <0.002-, 0.02- to 0.002-, 0.05- to 0.02 -, 0.25 - to 0.05 -, and 2- to 0.25 - $\mathrm{mm}$ fractions were 9.8, 31.2, $32.9,24.3$, and 1.8\% for LDM, and 17.9, 26.9, 27.2, 27.1, and $0.7 \%$ for SPM, respectively (Fig. 2, Fig. 3). Lower mean content of 2- to $0.25-\mathrm{mm}$ fraction was measured in the wet sieving procedure of SPM than did LDM (Fig. 2e, Fig. 3e). Higher mean contents of $<0.002$ (Fig. 2a, Fig. 3a) and 0.25- to 0.05-mm (Fig. 2 d, Fig. 3d) fractions, and meanwhile lower contents of 0.02 - to 0.002- (Fig. 2b, Fig. 3b) and 0.05- to 0.02-mm (Fig. 2c, Fig. 3c) size fractions were measured in the sedimentation procedure of SPM, in comparison with LDM.

Assigned with the USDA particle size limits, the mean clay, silt, and sand contents were 9.8, 64.1, and 26.1\% for LDM and $17.9,54.2$, and $27.8 \%$ for SPM, respectively. The contents of the clay fractions were lower for LDM than SPM for all 235 samples. Conversely, the contents of the silt fractions were generally higher for LDM than SPM (215 of 235 samples). The contents of the sand fractions were higher for LDM than SPM in 100 of the 235 samples. These results indicated that LDM underestimated clay content relative to SPM by an average of $45.1 \%$ but overestimated silt content by an average of $18.3 \%$ in the soils of the Loess Plateau, consistent with other findings for diverse soil textures (Loizeau et al., 1994; Konert and Vandenberghe, 1997; Eshel et al., 2004; Shein et al., 2006; Yang et al., 2009; Wang et al., 2013a). Beuselinck et al. (1998), however, reported that LDM underestimated the clay fraction of silty soils but generally overestimated the clay fraction of milled quartz samples, and Wu et al. (1993) and Muggler et al. (1997) reported agreement between the two methods.

The disagreements in PSDs between LDM and SPM could be explained by their different ways in defining particle sizes, and the heterogeneity of soil morphology and mineralogy. Matthews (1991) and Shein et al. (2006) assumed that the simplification of irregularly shaped particles into equivalent spheres would make the results of PSDs dependent on the analytical method. A coarser population of particles will probably be retained during sieving in SPM than the actual population with apparent diameters corresponding to the sieve size (Matthews, 1991), which could be partly supported by the measured lower content of 2- to $0.25-\mathrm{mm}$ fraction in the wet sieving procedure of SPM in comparison with LDM (Fig. 2e, Fig. 3e). The fine fraction is often overestimated during sedimentation, because the most stable position of a settling particle is when the maximum cross-sectional area is perpendicular to the direction of motion, which thus leads to decreased settling velocities of the particles (Krumbein, 1942). This may also be well approved by the measured higher clay $(<0.002 \mathrm{~mm})$ contents in the sedimentation procedure of SPM than did LDM (Fig. 2a, Fig. $3 a)$. The heterogeneity of particle density could be another source of error for SPM (Eshel et al., 2004), because SPM is 
practically based on Stokes' Law, which defines particle size mostly by density (Di Stefano et al., 2010). Particle density in SPM, however, is commonly assumed to be a constant
(2.65 $\mathrm{Mg} \mathrm{m}^{-3}$ ), which it is not true for soils (Clifton et al., 1999). A PSD will shift toward coarse fractions in LDM, because the projected cross-sectional area of a non-spherical particle
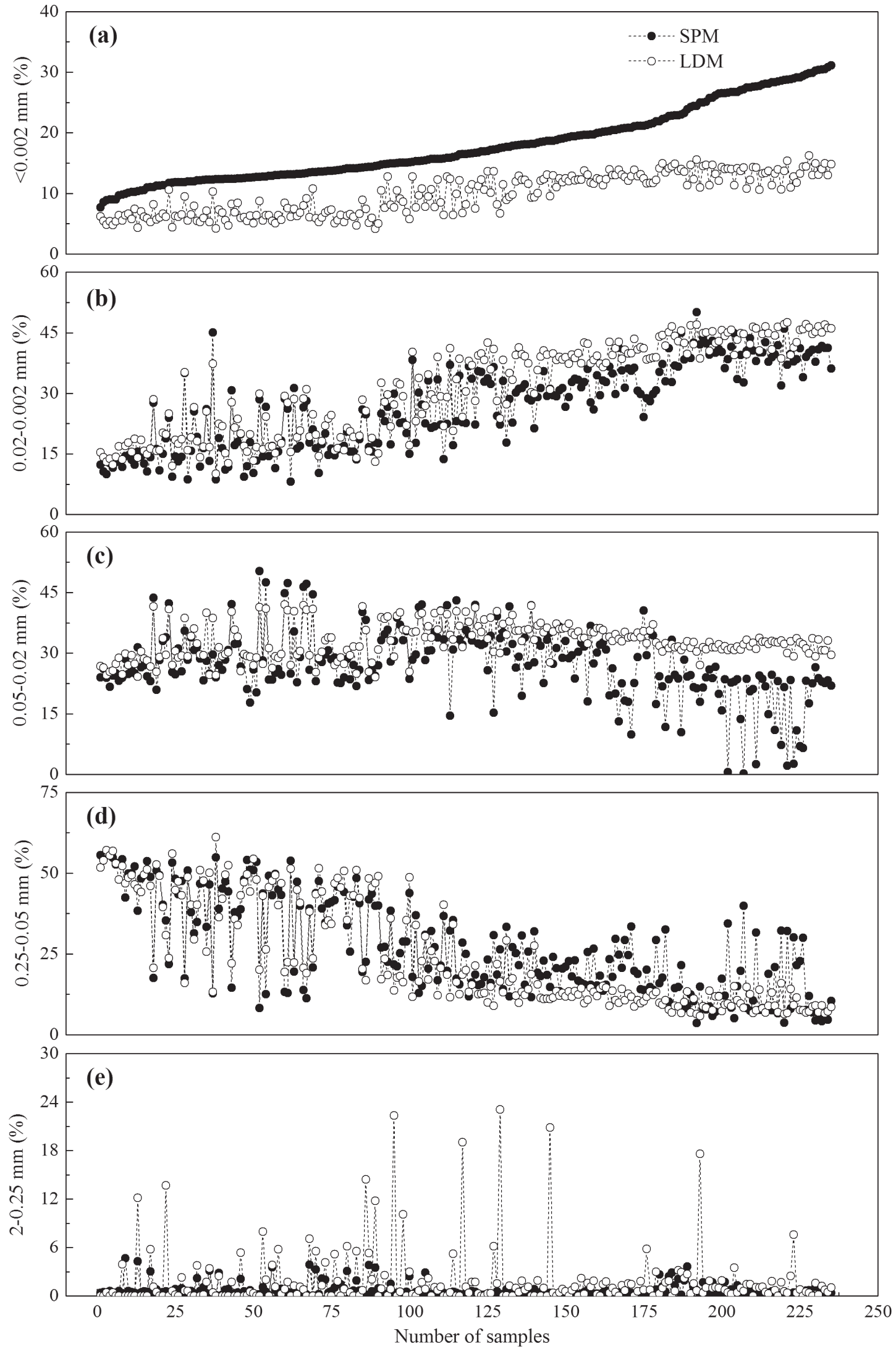

Fig. 2. Contents of the five size fractions determined by the sieve-pipette method (SPM) and the laser-diffraction method (LDM) for the collected 235 samples. Note: Soil samples were ordered by their clay contents. 
averaged over all possible orientations relative to the direction of the beam is larger than that of a sphere of equal volume (Jonasz, 1991). This shift causes the underestimation of clay content but the overestimation of coarse particles, as indicated by our results (Fig. 2, Fig. 3). However, we should bear in mind that both
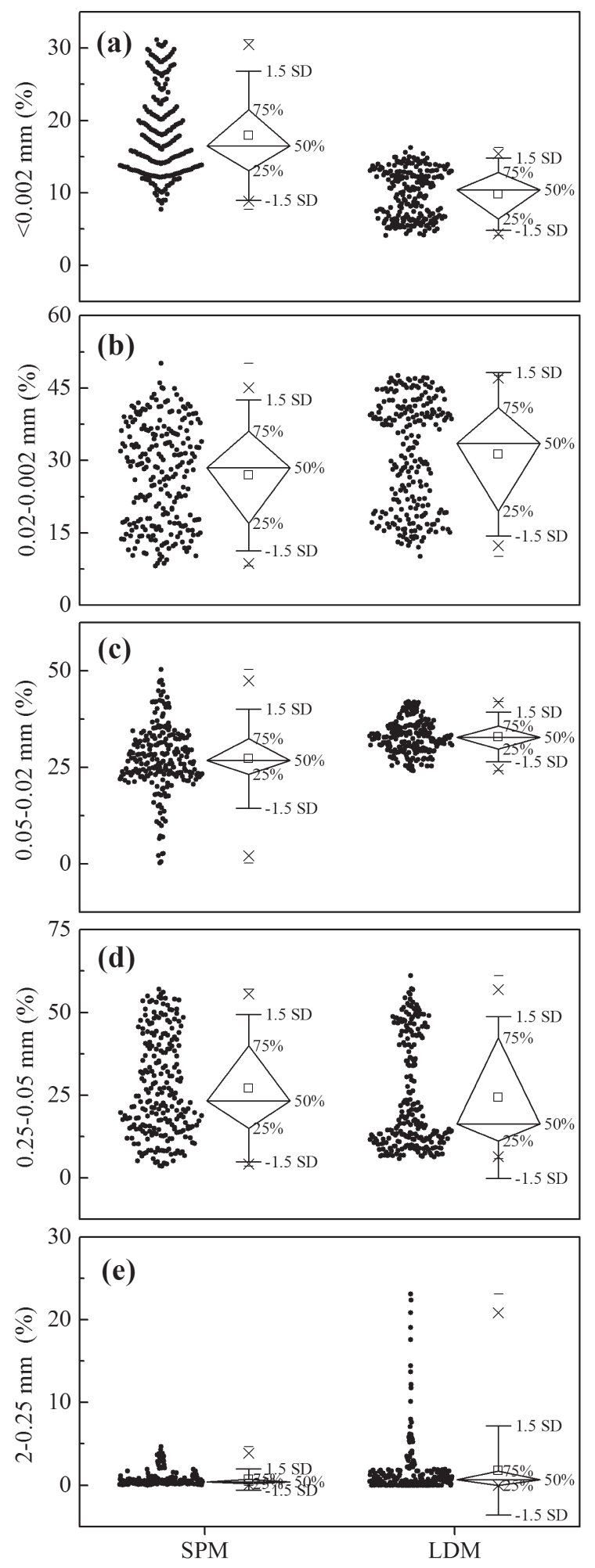

Fig. 3. Box charts of the contents of the five size fractions obtained by the sieve-pipette method (SPM) and the laser-diffraction method (LDM) for the collected 235 samples. Note: soil samples were ordered by their clay contents.
LDM and SPM just yield estimates of PSD due to the difficulty in defining the size of irregularly shaped particles. A PSD will shift toward fine fractions in the sedimentation procedure of SPM but conversely shift toward coarse fractions in LDM, as discussed above. More investigation is still needed to find out a reference method for accurately determining PSDs.

The coefficient Cs were positively correlated with clay contents but negatively correlated with sand contents $(P<$ 0.001; Table 2), indicating that the difference in the results of soil PSDs between the two methods would increase with increasing clay contents. If this pattern is general, differences of PSDs between LDM and SPM would be larger in fine than in coarse soils. The coefficient Cs were positively correlated with SOC contents $(P<0.001)$, probably due to the positive correlations between the SOC content and clay content $(r=$ $0.498, P<0.001)$. A higher SOC content, accompanied by higher clay contents, will produce larger errors in the PSDs derived by LDM and SPM.

The coefficient Cs between LDM and SPM also varied with land use $(F=3.33, P<0.05$; Fig. 4a). The values were larger for forests and croplands than grasslands $(P<0.05)$, which demonstrated that the difference in PSD data between the two methods would be larger for the soils collected from forests and croplands than from grasslands. This discrepancy could be due to the higher clay content in the forests and croplands than in the grasslands (Table 1).

\section{Relationships between Laser-Diffraction Method and Sieve-Pipette Method}

We used concatenate fitting that includes two thirds of the 235 soil samples collected from the three land uses for correlating the PSD data obtained by LDM and SPM. The volume percentages of $<0.002,0.02$ - to $0.002-, 0.05$ - to 0.02 -, and 0.25 to $0.05-\mathrm{mm}$ fractions obtained by LDM were all correlated with the mass percentages of those obtained by SPM $(P<0.001$; Fig. $5 \mathrm{a}-\mathrm{d})$. However, no significant correlation was observed for $2-$ to $0.25-\mathrm{mm}$ fraction between the volume percentage obtained by LDM and the mass percentage obtained by the wet sieving procedure in SPM (Fig. 5e).

Assigned with the USDA particle-size limits, the volume percentages of the clay, silt, and sand fractions obtained by LDM were all correlated with the mass percentages of those obtained by SPM, indicated by significant $R^{2}$ of $0.67,0.65$, and 0.79 , respectively $(P<0.001$; Table 3$)$. Considering of the fundamental requirement that the addition of the clay, silt, and sand contents should be $100 \%$ for measured samples, we did not use the established relationship model for silt content, due to its relatively lower $R^{2}$, to convert data from LDM to SPM. Instead, the silt content was indirectly calculated by subtracting the sum of clay and sand contents from $100 \%$ (Table 3).

The relationships of the PSD data between LDM and SPM fitted an exponential model for the clay fractions $(P<0.001$; Table 3, Fig. 5a), indicating that the underestimation of clay fractions by LDM would become increasingly significant with increasing 
Table 2. Correlation coefficients between the coefficient Cs and the physical and chemical properties of the soils. $t$

\begin{tabular}{|c|c|c|c|c|c|c|c|c|}
\hline & \multirow[b]{2}{*}{$\mathrm{D}_{\mathrm{B}}$} & \multirow[b]{2}{*}{ SOC } & \multicolumn{2}{|c|}{ Clay \% } & \multicolumn{2}{|c|}{ Silt \% } & \multicolumn{2}{|c|}{ Sand $\%$} \\
\hline & & & SPM & LDM & SPM & LDM & SPM & LDM \\
\hline Coefficient Cs & -0.001 & 0.317 & 0.662 & 0.546 & -0.014 & 0.481 & -0.255 & -0.501 \\
\hline$P$ & 0.990 & $<0.001$ & $<0.001$ & $<0.001$ & 0.835 & $<0.001$ & $<0.001$ & $<0.001$ \\
\hline
\end{tabular}

$\mathrm{f}_{\mathrm{B}^{\prime}}$ bulk density; SOC, soil organic carbon; SPM, sieve-pipette method; LDM, laser-diffraction method.

contents of clay fractions. This result was well supported by the report that a laser particle-size analysis underestimated the clay content relative to the classical sedimentation method, and this underestimation increased with increasing clay content (Loizeau et al., 1994). Our exponential fitting between the two methods for the clay fractions, however, disagreed with previously reported linear fittings (Konert and Vandenberghe, 1997; Beuselinck et al., 1998; Eshel et al., 2004; Yang et al., 2009; Wang et al., 2013a). This discrepancy may have been caused by differences in pre-treatment, dispersion, optical theory, optical parameters, or particle mineralogy or morphology (Özer et al., 2010).

The ANOVA indicated that the three typical land uses did not affect the coefficient Cs between the SPM-measured and LDM-converted PSD data $(F=0.590, P=0.557$; Fig. $4 \mathrm{~b})$. The relationships between the clay, silt, and sand fractions obtained by LDM and SPM presented a general pattern among the land uses. We can thus use the relationships to convert PSD data from LDM (volume, \%) to SPM (mass, \%), independent of the type of land use.

\section{Rapid Determination of Soil Texture by Laser- Diffraction Method-derived Particle-Size Distributions}

We converted volume percentages of the clay, silt, and sand fractions obtained by LDM to the mass percentages used by SPM, for one third (78 samples) of the whole date set, based on the above relationship models (Table 3). These soil samples covered three land uses and diverse PSD distributions, and thus could be good representatives of the peculiarities of the 235 collected samples.

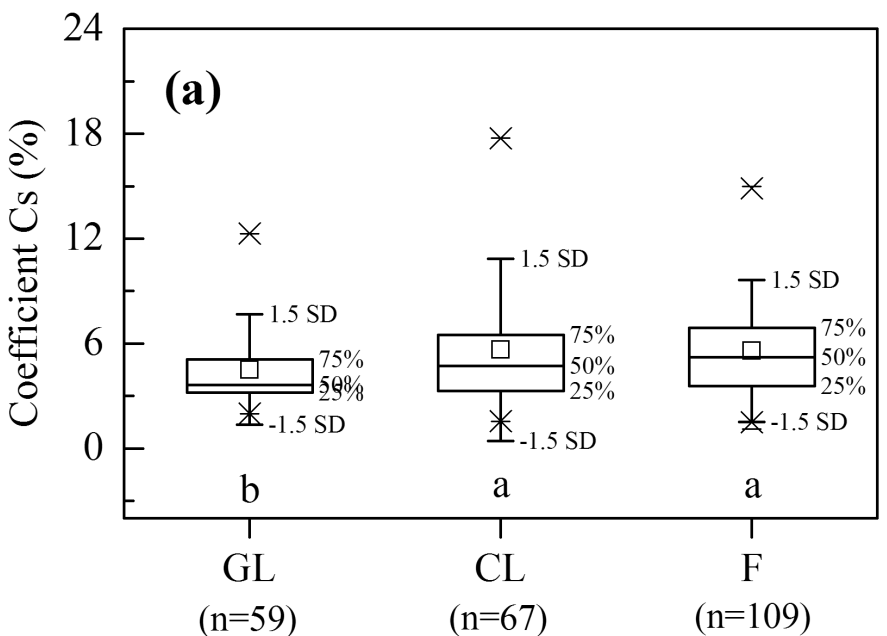

Converting PSD data from LDM (volume, \%) to SPM (mass, \%) decreased the mean coefficient C from $7.9 \%$ between the LDM- and SPM-measured data to $4.1 \%$ between the measured and calculated data (Fig. 6). The small errors between the measured and calculated PSD data successfully tested our calibration models and strongly supported the feasibility of PSD conversion for data comparison. However, it should be noted that it is still comparing one highly inaccurate method to another one, maybe more accurate, but still with some systematic errors. After the conversion, the mass percentages of the clay, silt, and sand contents estimated by LDM data using the above relationship models, displayed in good agreements with those measured by classical SPM, indicated by high $R^{2}$ of $0.805,0.716$, and 0.771 and low relative mean squared error (RMSE) of 2.71, 6.61, and 7.07, respectively (Fig. $7 \mathrm{a}-\mathrm{c}$ ).

The distributions of soil texture within the USDA textural triangle agreed well in 71 of the 78 samples for the measured and calculated values, after the PSD conversion from LDM (volume, \%) to SPM (mass, \%; Table 4, Fig. 8). This good agreement was also indicated by the high kappa coefficient of $0.694(P<0.001)$, and thus provided strong support to our previously established relationship models (Table 3 ). The texture of a soil can thus be rapidly determined by converting LDM-derived data (volume, \%) to SPM-derived data (mass, \%), based on these relationship models.

\section{CONCLUSIONS}

We collected a total of 235 soil samples from three land uses and diverse soil textures at six sites on the Loess Plateau

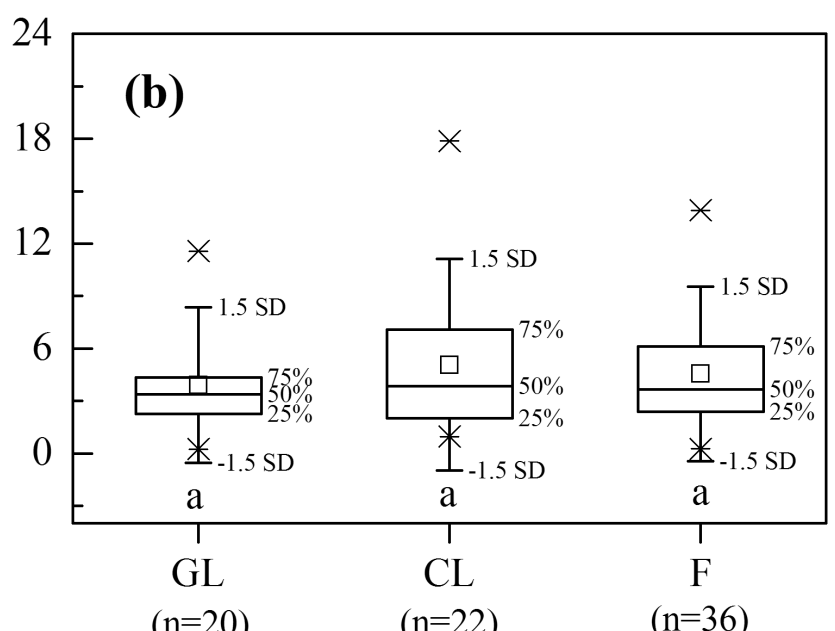

$(n=20)$

$(n=22)$

$(\mathrm{n}=36)$

Fig. 4. Box charts of the coefficient Cs between the laser-diffraction method (LDM)- and sieve-pipette method (SPM) measured particle-size distributions (PSDs) (a) for the 235 soil samples, and between the converted and measured PSDs (b) for the 78 validating soil samples. GL, Grassland; $\mathrm{CL}$, Cropland; F, Forest. Note: Different letters in the same panel indicate significant differences at $\boldsymbol{P}<0.05$. 

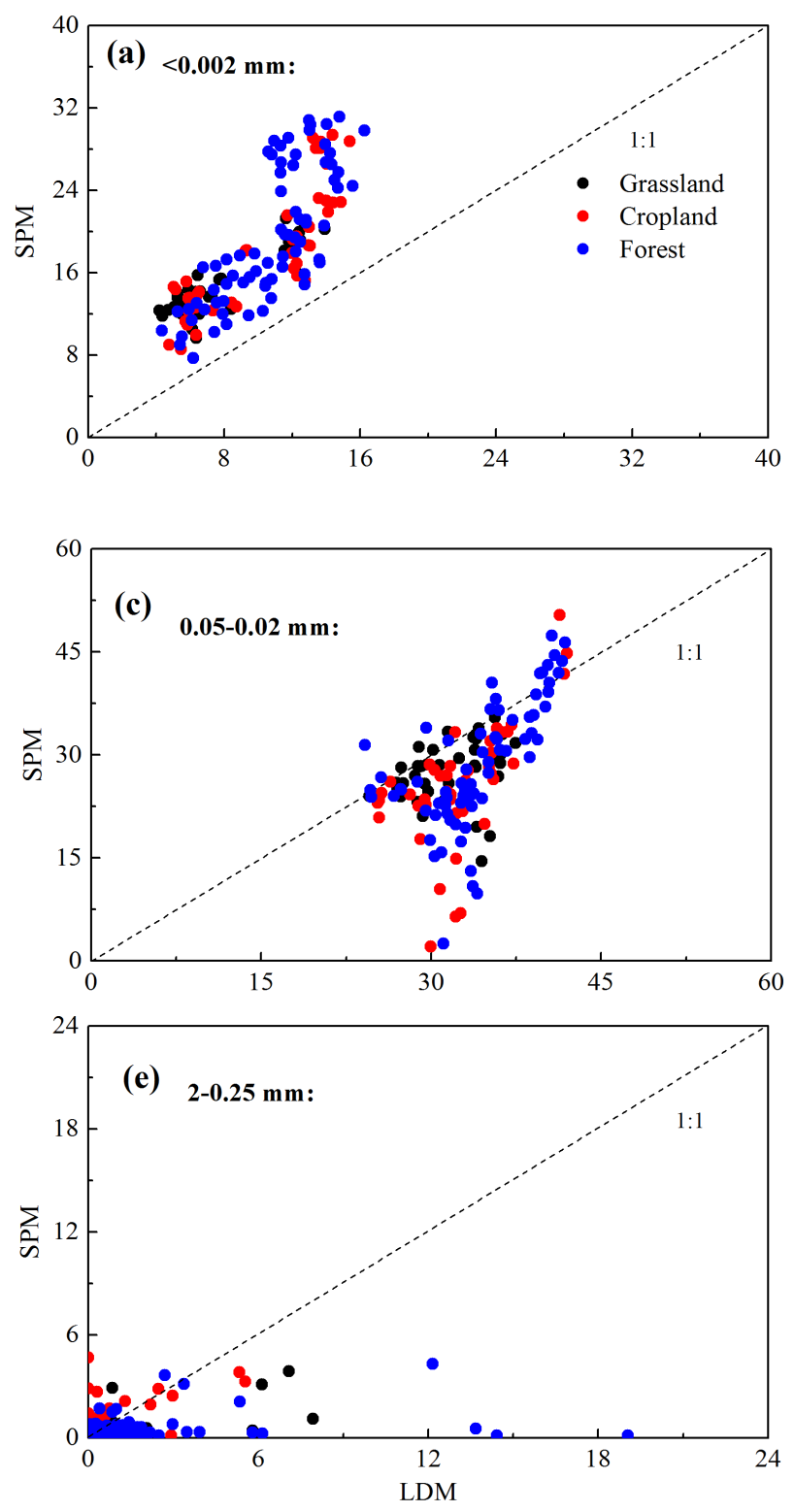

of China and compared the PSD data obtained by LDM and the classical SPM. The LDM underestimated clay contents by an average of $45.1 \%$ and overestimated silt contents by an average of $18.3 \%$ compared with SPM. The differences of PSDs between LDM and SPM, indicated by the coefficient Cs, were all positively correlated with the clay contents, which demonstrated that difference in PSDs between the two methods would be larger in fine than in coarse soils. Landuse type did not affect the difference of PSDs between the
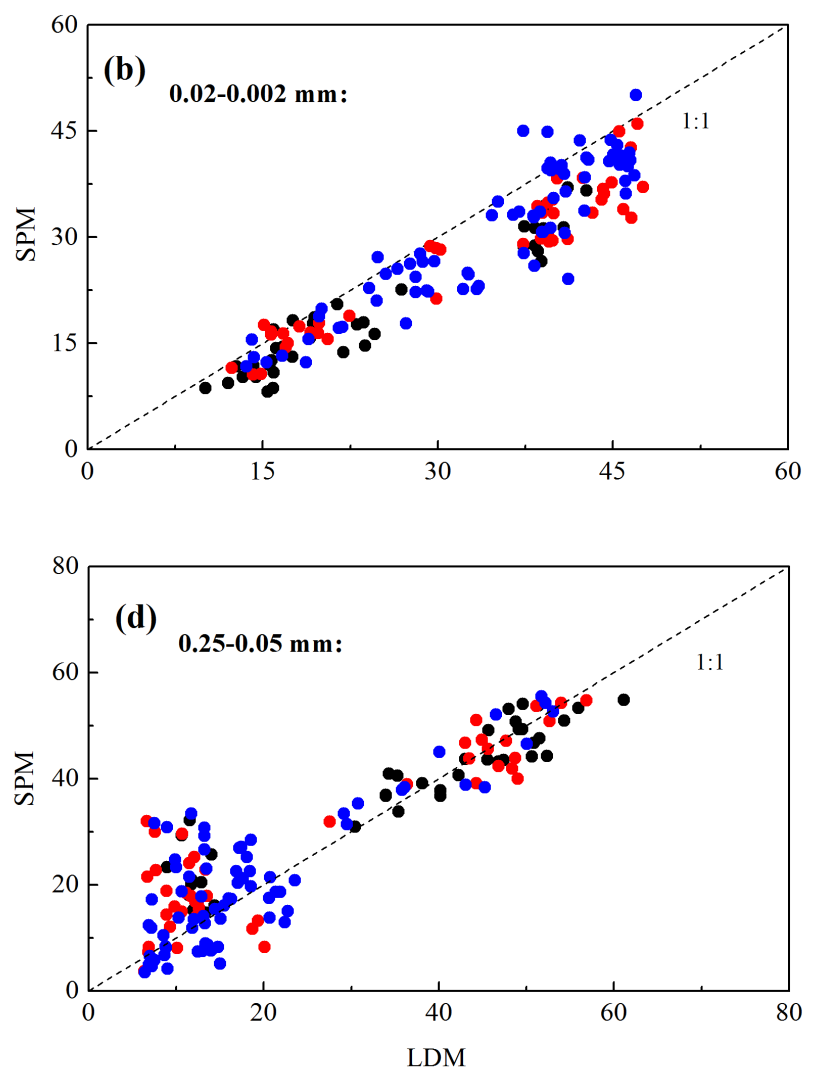

Fig. 5. Scatter diagrams of contents of the five size fractions derived by the sieve-pipette method (SPM) and the laser-diffraction method (LDM), for the 157 calibrating soil samples.

SPM-measured and LDM-converted PSD data $(P>0.05)$. The clay, silt, and sand contents derived by LDM and SPM were individually but not collectively correlated. Their relationships could be described as:

1. Estimated Clay $_{S P M}=2.17+5.76 \exp (0.10$ Measured

$$
\begin{aligned}
& \text { Clay } \left._{\text {LDM }}\right) \\
& \left(R^{2}=0.67, P<0.001\right)
\end{aligned}
$$

2. Estimated Sand $\mathrm{SPM}_{\mathrm{SP}}=6.83+0.81$ Measured Sand $\mathrm{LDM}_{\mathrm{LD}}$

Table 3. Established relationship models for converting PSD data from LDM (volume, \%) to SPM (mass, \%), based on two thirds of the whole data set. +

Equations

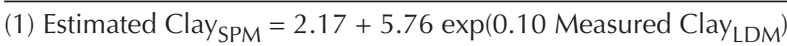

(2) Estimated Silt SPM $=10.3+0.68$ Measured Silt LDM

(3) Estimated Sand SPM $=6.83+0.81$ Measured Sand LDM

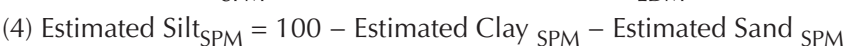
effect $(P>0.05)$. Additionally, to meet the fundamental requirement that the addition of the clay, silt, and sand contents should be $100 \%$ for measured samples, the above established Eq. [2], due to its relatively lower $R^{2}$, was not used for calculating the silt contents. We indirectly estimated the silt contents using the Eq. [4], that is, by subtracting the clay and sand contents from $100 \%$. 


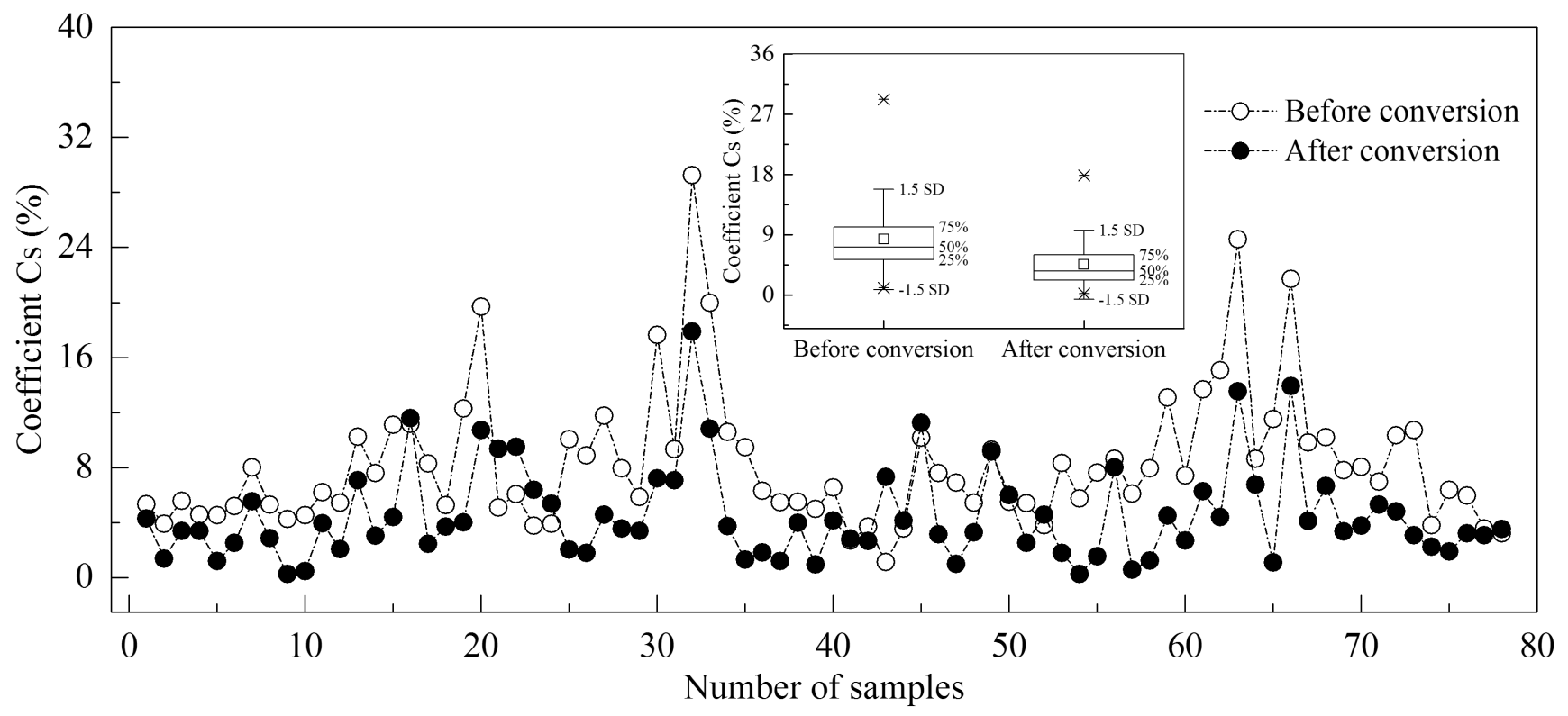

Fig. 6. Coefficient Cs in the particle-size distribution (PSD) data between the sieve-pipette method (SPM) and the laser diffraction method (LDM) for the 78 validating soil samples, before and after conversion.
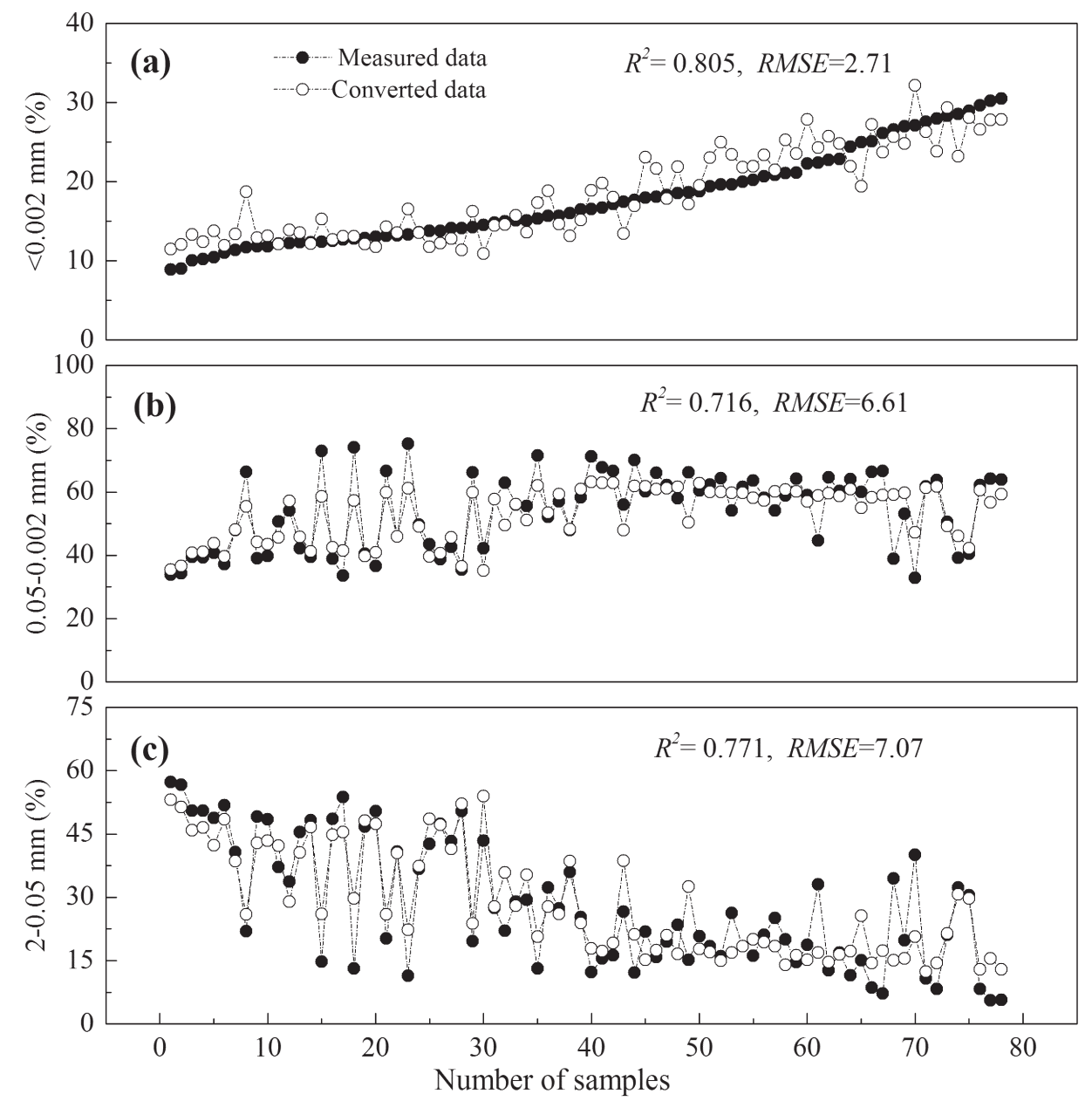

Fig. 7. Measured and converted values of the clay, silt, and sand contents for the 78 validating soil samples. Note: Soil samples were ordered by their clay contents. 
Table 4. Confusion matrixes illustrating the accuracy in correctly assigning the textural class of the 78 soil samples, starting from either Laser-differaction method (LDM) converted data or sieve-pipette method (SPM) measured data. $†$

\begin{tabular}{cccccccc} 
& & \multicolumn{7}{c}{ SPM measured PSDs } & \\
\cline { 3 - 7 } & & SAL & L & SIL & SCL & CL & Total \\
\hline \multirow{5}{*}{ LDM converted PSDs } & SAL & 1 & 2 & 0 & 0 & 0 & 3 \\
& L & 1 & 19 & 2 & 0 & 0 & 22 \\
& SIL & 0 & 3 & 39 & 1 & 0 & 43 \\
& SCL & 0 & 0 & 4 & 2 & 0 & 6 \\
& CL & 0 & 1 & 0 & 0 & 3 & 4 \\
& Total & 2 & 25 & 45 & 3 & 3 & 78 \\
\hline
\end{tabular}

† PSD, particle-size distribution; SAL, Sandy loam; L, Loam; SIL, Silty loam; SCL, Silty clay loam; CL, Clay loam.

$$
\left(R^{2}=0.79, P<0.001\right)
$$

\section{Estimated Silt $_{\mathrm{SPM}}=100-$ Estimated Clay $_{\mathrm{SPM}}-$ Estimated Sand ${ }_{\text {SPM }}$}

These models provide a feasible way to convert PSD data from LDM (volume, \%) to SPM (mass, \%) for data comparison. After conversion, good agreements in the distribution of soil textures were observed in 71 of the 78 validation samples for measured and converted data, as evidenced by the high kappa coefficient of $0.694(P<0.001)$. Soil texture can thus be rapidly determined with good precision by using the PSD data obtained by LDM, based on this conversion.

\section{ACKNOWLEDGMENTS}

We are grateful to Chencheng Zhang and Changkun Ma for their kind help in field soil sampling and to the anonymous reviewers for their valuable comments which greatly improved the quality of the manuscript. This study was financially supported by the National Natural Science Foundation of China $(41271315$, 41571296), the Program for New Century Excellent Talents in University (NCET-130487), and programmes of Northwest A\&F University (2014YQ007) and the Institute of Soil and Water Conservation, Chinese Academy of Sciences and Ministry of Water Resources (A315021381).

\section{REFERENCES}

Allen, T. 1981. Particle size measurement. 3rd ed. Chapman and Hall, New York. Arya, L.M., and J.F. Paris. 1981. A physicoempirical model to predict the soil moisture characteristic from particle-size distribution and bulk density data. Soil Sci. Soc. Am. J. 45:1023-1030. doi:10.2136/ sssaj1981.03615995004500060004x

Bah, A.R., O. Kravchuk, and G. Kirchhof. 2009. Fitting performance of particle-size distribution models on data derived by conventional and laser diffraction techniques. Soil Sci. Soc. Am. J. 73:1101-1107. doi:10.2136/ sssaj2007.0433

Beuselinck, L., G. Govers, J. Poesen, G. Degraer, and L. Froyen. 1998. Grainsize analysis by laser diffractometry: Comparison with the sieve-pipette method. Catena 32:193-208. doi:10.1016/S0341-8162(98)00051-4

Bishop, Y.M.M., S.E. Fienberg, and P.W. Holland. 1975. Discrete multivariate analysis: Theory and practice. M.I.T. Press, Cambridge, MA.

Campbell, J.R. 2003. Limitations in the laser particle sizing the soils. In: I.C. Roach, editor, Advances in regolith. CRC LEME, Canberra, Australia. p. $38-42$.

Cheetham, M.D., A.F. Keene, R.T. Bush, L.A. Sullivan, and W.D. Erskine. 2008. A comparison of grain-size analysis methods for sand-dominated fluvial sediments. Sedimentology 55:1905-1913. doi:10.1111/j.1365$\underline{3091.2008 .00972 . x}$

Clifton, J., P. McDonald, L. Plater, and F. Oldfield. 1999. An investigation into the efficiency of particle size separation using Stocks' law. Earth Surf. Processes Landforms 24:725-730. doi:10.1002/(SICI)1096-

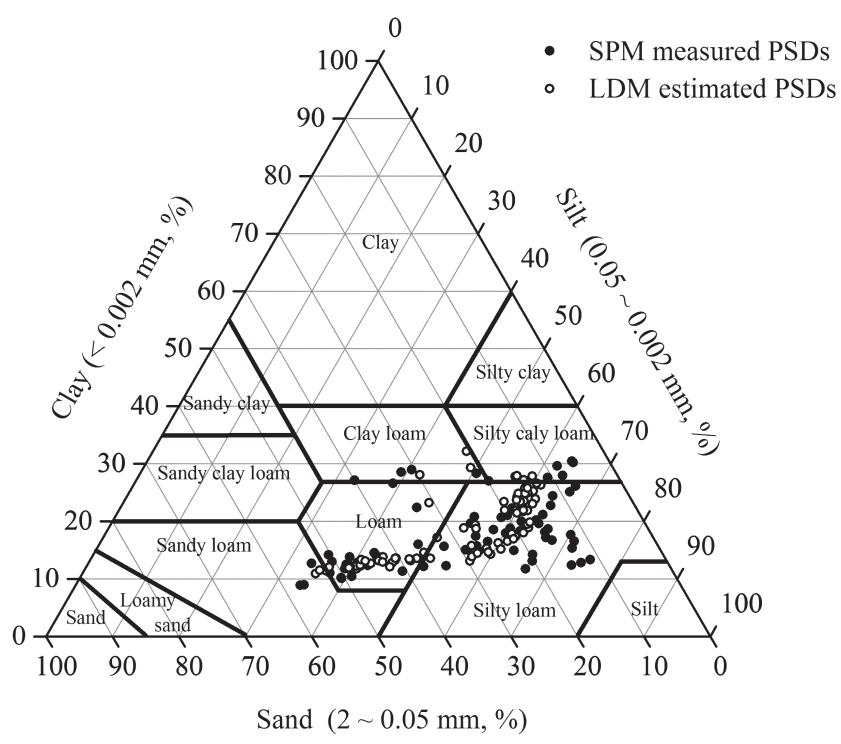

Fig. 8. Distribution of soil textures in the USDA textural triangles based on measured- and converted-particle-size distribution (PSD) data for the $\mathbf{7 8}$ validating soil samples.

\section{7(199908)24:8<725::AID-ESP5>3.0.CO 2 -W}

Cooper, L.R., R.L.Haverland,D.M. Hendricks, and W.G. Knisel. 1984. Microtrac particle size analyzer: An alternative particle size determination method for sediment and soil. Soil Sci. 138:138-146. doi:10.1097/00010694198408000-00007

De Boer, G.B., C. de Weerd, D. Thoenes, and H.W. Goossens. 1987. Laser diffraction spectrometry: Fraunhofer diffraction versus Mie scattering. Part. Char. 4:14-19.

Di Stefano, C., V. Ferro, and S. Mirabile. 2010. Comparison between grain-size analyses using laser diffraction and sedimentation methods. Biosystems Eng. 106:205-215. doi:10.1016/j.biosystemseng.2010.03.013

Eshel, G., G.J. Levy, U. Mingelgrin, and M.J. Singer. 2004. Critical evaluation of the use of laser diffraction for particle-size distribution analysis. Soil Sci. Soc. Am. J. 68:736-743. doi:10.2136/sssaj2004.7360

Gee, G.W., and J.W. Bauder. 1986. Particle-size analysis. In: A. Klute, editor, Methods of soil analysis. Part 1. 2nd ed. Agron. Monogr. No. 9. ASA and SSSA, Madison, WI. p. 383-411.

Gee, G.W., and D. Or. 2002. Particle-size analysis. In: J.H. Dane and G.C. Topp, editors, Methods of soil analysis. Part 4. Physical methods. SSSA Book Ser. 5. SSSA, Madison, WI. p. 255-294.

Goossens, D. 2008. Techniques to measure grain-size distributions of loamy sediments: A comparative study of ten instruments for wet analysis. Sedimentology 55:65-96.

Hajnos, M., J. Lipiec, R. Świeboda, Z. Sokołowska, and B. Witkowska-Walczak. 2006. Complete characterization of pore size distribution of tilled and orchard soil using water retention curve, mercury porosimetry, nitrogen adsorption, and water desorption methods. Geoderma 135:307-314. doi:10.1016/j.geoderma.2006.01.010

Jonasz, M. 1991. Size, shape, composition and structure of micro-particles from light scatting. In: J.P.M. Syvitski, editor, Principles, methods, and the applications of particle size analysis. Cambridge Univ. Press, Cambridge. p. $143-162$.

Konert, M., and J.E.F. Vandenberghe. 1997. Comparison of laser grain size analysis with pipette and sieve analysis: A solution for the underestimation of the clay fraction. Sedimentology 44:523-535. doi:10.1046/j.1365-3091.1997. d01-38.x

Kowalenko, C.G., and D. Babuin. 2013. Inherent factors limiting the use of laser diffraction for determining particle size distributions of soil and related samples. Geoderma 193:22-28. doi:10.1016/j.geoderma.2012.09.006

Krumbein, W.C. 1942. Settling-velocity and flume-behavior of non-spherical particles. Trans. Am. Geophys. Union 23:621-633.

Loizeau, J.L., D. Arbouille, S. Santiago, and J.P. Vernet. 1994. Evaluation of a wide range laser diffraction grain size analyser for use with sediments. Sedimentology 41:353-361. doi:10.1111/j.1365-3091.1994.tb01410.x

Makó, A., K. Rajkai, H. Hernádi, and G. Hauk. 2014. Comparison of different 
settings and pre-treatments in soil particle size distribution measurement by laser-diffraction method. Agrokemia es Talajtan 63:19-28.

Matthews, M.D. 1991. The effect of grain shape and density on the size measurement. In: J.P.M. Syvitski, editor, Principles, methods, and the applications of particle size analysis. Cambridge Univ. Press, Cambridge. p. 22-33.

Miller, B.A., and R.J. Schaetzl. 2012. Precision of soil particle size analysis using laser diffractometry. Soil Sci. Soc. Am. J. 76:1719-1727. doi:10.2136/ $\underline{\text { sssaj2011.0303 }}$

Muggler, C.C., T. Pape, and P. Buurman. 1997. Laser grain-size determination in soil genetic studies 2. Clay content, clay formation, and aggregation in some Brazilian oxisoils. Soil Sci. 162:219-228. doi:10.1097/00010694199703000-00008

Nelson, D.W., and L.E. Sommers. 1982. Total carbon, organic carbon, and organic matter. In: A.L. Page et al., editors, Methods of soil analysis, Part 2. Agron. Monogr. No. 9. ASA and SSSA, Madison, WI. p. 539-552.

Özer, M., M. Orhan, and N.S. Işik. 2010. Effect of particle optical properties on size distribution of soils obtained by laser diffraction. Environ. Eng. Geosci. 16:163-173. doi:10.2113/gseegeosci.16.2.163

Ramaswamy, V., and P. Rao. 2006. Grain size analysis of sediments from the northern Andaman Sea: Comparison of laser diffraction and sieve-pipette techniques. J. Coast. Res. 224:1000-1009. doi:10.2112/04-0162.1

Ryżak, M., and A. Bieganowski. 2011. Methodological aspects of determining soil particle-size distribution using the laser diffraction method. J. Plant Nutr. Soil Sci. 174:624-633. doi:10.1002/jpln.201000255

Shein, E.V., E.Y. Milanovskii, and A.Z. Molov. 2006. The effect of organic matter on the difference between particle-size distribution data obtained by the sedimentometric and laser diffraction methods. Eurasian Soil Sci. 39:S84S90. doi:10.1134/S106422930613014X

Singer, J.K., J.B. Anderson, M.T. Ledbetter, I.N. McCave, K.P.N. Jones, and R. Wright. 1988. An assessment of analytical techniques for the size analysis of fine-grained sediments. J. Sediment. Res. 58:534-543.

Sochan, A., C. Polakowski, and Ł. Grzegorz. 2014. Impact of optical indices on particle size distribution of activated sludge measured by laser diffraction method. Ecol. Chem. Eng. S 21:137-145.
Vdović, N., J. Obhođaš, and K. Pikelj. 2010. Revisiting the particle-size distribution of soils: Comparison of different methods and sample pre-treatments. Eur. J. Soil Sci. 61:854-864. doi:10.1111/j.13652389.2010.01298.x

Vitton, S.J., and L.Y. Sadler. 1997. Particle-size analysis of soils using laser light scattering and X-ray absorption technology. ASTM Geotech. Test. J. 20:63-73. doi:10.1520/GTJ11421J

Wang, W.P., J.L. Liu, J.B. Zhang, X.P. Li, Y.N. Cheng, W.W. Xin, and Y.F. Yan. 2013a. Evaluation of laser diffraction analysis of particle size distribution of typical soils in China and comparison with the Sieve-Pipette method. Soil Sci. 178:194-204. doi:10.1097/SS.0b013e31829908be

Wang, Y.Q., M.A.Shao, and Z.P. Liu. 2013b. Vertical distribution and influencing factors of soil water content within $21-\mathrm{m}$ profile on the Chinese Loess Plateau. Geoderma 193:300-310. doi:10.1016/j.geoderma.2012.10.011

Wei, X.R., X.Z. Li, X.X. Jia, and M.A. Shao. 2013a. Accumulation of soil organic carbon in aggregates after afforestation on abandoned farmland. Biol. Fertil. Soils 49:637-646. doi:10.1007/s00374-012-0754-6

Wei, X.R., M.A. Shao, W. Gale, X.C. Zhang, and L.H. Li. 2013b. Dynamics of aggregate-associated organic carbon following conversion of forest to cropland. Soil Biol. Biochem. 57:876-883. doi:10.1016/j. soilbio.2012.10.020

Wei, X.R., M.A. Shao, W. Gale, and L.H. Li. 2014. Global pattern of soil carbon losses due to the conversion of forests to agricultural land. Sci. Rep. 4:4062 doi: $10.1038 /$ srep04062.

Wen, B., A. Aydin, and N.S. Duzgoren-Aydin. 2002. A comparative study of particle size analyses by sieve-hydrometer and laser diffraction methods. ASTM Geotech. Test. J. 25:434-442.

Wu, Q., M. Borkovec, and H. Sticher. 1993. On particle-size distributions in soils. Soil Sci. Soc. Am. J. 57:883-890. doi:10.2136/ sssaj1993.03615995005700040001x

Yang, J.L., G.L. Zhang, D.C. Li, and J.H. Pan. 2009. Relationships of soil particle size distribution between sieve-pipette and laser diffraction methods.(In Chinese with English abstract.) Acta Pedologica Sinica 46:772-780 .

Zobeck, T.M. 2004. Rapid soil particle size analyses using laser diffraction. Appl. Eng. Agric. 20:633-639. doi:10.13031/2013.17466 